Fiction lagging behind or non-fiction defending the indefensible? University-industry (et al.) interaction in science fiction 


\title{
Fiction Lagging Behind Or Non-Fiction Defending The Indefensible? University-Industry (et al.) Interaction In Science Fiction
}

\author{
Joaquín M. Azagra-Caro ${ }^{1, *}$, Laura González-Salmerón ${ }^{2}$, Pedro Marques ${ }^{1}$ \\ ${ }^{1}$ INGENIO (CSIC-Universitat Politècnica de València), Valencia (Spain) \\ ${ }^{2}$ Faculty of Medieval and Modern Languages, University of Oxford
}

\begin{abstract}
University-industry interaction has many supporters and some detractors in the scholarly literature. Framings for science, technology and innovation (STI) policy emphasise that universities interact with stakeholders other than industry and that these interactions contribute to a wide set of goals, such as environmental sustainability. Given the importance of discourse to shape public opinion, we wonder whether academic and policy actors have transmitted this positive attitude towards university interactions. We seek the answer in the representation of university interactions in popular culture. Because public opinion conversely shapes science, we also ask whether this method opens new research questions. Our sample is science fiction novels that have won three of the most prestigious awards in the genre (Hugo, Nebula and Locus), from the 1970s to date. The use of an objective corpus of the literature increases external validity, a methodological novelty in the study of the representations of science. We illustrate how science fiction has been predominantly critical to university interactions, indicating the lack of a convincing institutional narrative about their benefits. In particular, fears to interaction with industry and other stakeholders are equivalent. Other insights include the recommendation for studies on knowledge transfer policy to incorporate critical views of university-industry interaction, including threats to sustainability; the opening of new research questions regarding the defence of non-disclosure of information for political reasons; and visionary examples of conflicts of equity due to the lack of promotion of 'disengaged' academics.
\end{abstract}

Keywords: university-industry interaction, research stakeholders, conflicts, representations of science

*Corresponding author. Tel.: +34963877007; fax: +34963877991. E-mail address: jazagra@ingenio.upv.es 


\section{Introduction}

University research should be useful for the progress of firms. At the same time, private interests should not dominate public research agendas. Many of our societies live this tension, and strike a balance that evolves according to the juncture. Academics contribute to the debate, and nowadays the specific literature on university-industry interaction has tended to consider that its advantages outweigh its disadvantages. The broader field of Science, Technology and Innovation (STI) Studies is even more positive, and current framings for STI policy stress that university interactions with multiple stakeholders (not only industry) are mainly beneficial, in particular for the sustainability of socioeconomic systems. Political authorities have largely endorsed this support for university interactions, which often shows up in policy briefs, and probably aspires to be in tune with the citizenship. Given the importance of political discourse to shape public opinion, we wonder: is this predominantly positive view shared with people outside academia?

We propose to answer this question through the analysis of the representations of university-industry interaction in popular culture. We choose specifically science fiction for its proximity to the topic, its impact on people expectations about technology (Kirby, 2010) and its superior capacity to predict the effects technology in context to that of technical studies (Miller and Bennet, 2008). STI Studies have incipiently used science fiction to establish analogies with its typical objects of analysis, namely the sources of innovation (Basset et al., 2013) or its rate and direction (Archibugi, 2017; Steinmueller, 2017). However, the field has not analysed the representations of these objects per se. Cultural Studies are 'the best proxy' for this type of analysis. The usual work includes representations of researchers in popular culture, e.g. literary fiction in general (Haynes, 1989), Victorian and Edwardian novels (Russell, 2007), science fiction novels (Bowman, 2007), movies in general (Weingart, 2003), Hollywood comedies (Terzian and Grunzke, 2007), superhero comics (Locke, 2005), etc. The characteristic result is an ambivalent portrayal of researchers, from the archetypical dichotomy between the harmless absentminded professor and the mad genius, to more complex distinctions. This resonates with the ambivalent understanding of university-industry interaction, but the typical work in Cultural Studies deals with the world of science in isolation, without considering its 
interaction with industry. This field understands that literature shapes contemporary attitudes to science and scientists as much as it is shaped by them (Huxford, 2000). Because public opinion shapes science, we also ask: could the study of 'fiction' open new research avenues for university-industry studies?

The study of 'representations' of socioeconomic phenomena in fiction enriches their analysis, as the concomitant field of Organizational Studies acknowledges: Borges' short stories or science fiction novels offer lessons to researchers (De Cock, 2000; Pick, 2016). Fiction is a laboratory for experimenting with many plausible situations, unconstrained by reality, but shaped according to creators' mental models. Thus, fictional representations of socioeconomic phenomena produce empirical evidence that is connected with (and sometimes mimics) reality. Even superheroes create networks with similar topographic properties to those of humans (Alberich et al., 2002)!

We hereby analyse the representation of university-industry interaction in popular culture, paying particular attention to its advantages and disadvantages as depicted in science fiction works. Our expectation is to examine whether fiction producers share the predominantly positive view of scholars and policymakers, and new research avenues for the literature on university-industry interaction.

\section{Advantages and disadvantages of university-industry interaction}

\subsection{Advantages of university-industry interaction}

University-industry interaction is useful for academics, firms and the economy. It makes academics earn personal income, gain awareness of general economic needs and orient their research towards applied goals. It may connect them to industrial researchers with specialised frontier knowledge, improve their scientific impact (Balconi and Laboranti, 2006; Tijssen, 2018), and widen their network so that more opportunities to get funding and find professional exits for their students and collaborators arise (MeyerKrahmer and Schmoch, 1998; Meng et al., 2019; Henningsson and Geschwind, 2019). For firms, interaction with universities may bring familiarity with state-of-the-art ideas, the chance to sub-contract work which would be too costly to develop in-house, or 
indirect benefits derived from signalling the ability to collaborate: attraction of good scientists, strategic alliances with other firms and a better position to get R\&D grants (Santoro and Chakrabarti, 2002; Azagra-Caro et al., 2014; Maietta, 2015; Guerrero et al., 2019). This mutual reinforcement between universities and companies enhances the value of academic activities for the region and the country, legitimises the role of universities, translates into competitive advantage, knowledge flows, technological innovation and economic growth (Caiazza et al., 2015; Azagra-Caro and Consoli, 2016; Voutsinas et al., 2018, Ghio et al., 2019; Zhang et al., 2019), and becomes an asset in the face of globalization (Audretsch et al., 2014).

In a similar fashion, national governments, and the European Commission typically mention university-industry interaction as a necessary condition for growth and welfare. Eventually more and more innovative financial instruments have emerged to support university-industry interaction, like crowdfunding, startup accelerators, proof-of-concept centres, university-based seed funds, and intellectual property-backed financial instruments (Audretsch et al., 2016). Measures related to university-industry interaction, such as scientific output in the form of co-publications are considered in international rankings of universities (Tijssen et al., 2016).

\subsection{Current framings for STI policy: from industry to multiple stakeholders and sustainability}

Many conceptual models of the 1990s about the science or innovation processes incorporated university-industry interaction among the motors of well-functioning societies, e.g. national systems of innovation (Nelson, 1993; Lundvall, 2010), the Mode 2 of knowledge production (Nowotny et al., 1994), the Triple Helix (Etzkowitz and Leydesdorff, 2000), the entrepreneurial university (Clark, 1998) or the third mission of universities (Molas-Gallart et al., 2002). These approaches differ in the importance granted to universities in the innovation process, but do not question that some degree of interaction with firms should exist.

This view continues in current conceptual frameworks of STI policies. The 'productive interactions' approach argues that if there is learning during the course of a relationship between researchers and other stakeholders, this learning can account for social impact of research (Spaapen and Van Drooge, 2011: notably, most of the examples 
given by these authors involve university researchers and industry stakeholders). The literature on 'societal impact of research' cares about the problem of measuring and assessing the returns of public science, but largely relies on the assumption that the impact is positive if leading to innovation (Bornmann, 2013). Similarly, the 'responsible research and innovation' (RRI) approach conceives scientific impact through interaction with industry and society as the basis for innovation (Von Schomberg, 2013). However, new paradigms like 'Responsible Research and Innovation' are sometimes wishful thinking that justify policy support to university-industry interactions which ultimately lead to bad praxis (Cooke, 2018). The 'transformative change' frame revises how much innovation policy and innovation actors' perspectives should change to achieve sociotechnical system transitions towards sustainable growth, but admits that the publicprivate interactions were well conducted by previous theoretical approaches or by contemporary ones, like 'societal impact of research' or 'RRI' (Schot and Steinmueller, 2018).

Notice that most of these frames prefer the term 'stakeholders' of the science system to 'university-industry interaction'. This emphasises how the relevance of public researchers transcends their impact on industry to cover other sectors of performance, notably society, citizenship or cultural agents (as also acknowledged by the Quadruple Helix framework: Carayannis and Campbell, 2009), but also hospitals, the military, nongovernmental organizations, etc. Actually, some literature is exploring the contact between academic researchers and unusual fora, like diplomatic circles (Fähnrich, 2015), political parties (Parker, 2015) or the literary world (Azagra-Caro et al., 2018).

These approaches have nurtured together with the concern that sustainability of socioeconomic activities must guide everybody's agenda. In this context, universityindustry interaction as a precondition of 'sustainable' knowledge production is widely acknowledged (Bjursell and Engström, 2019; Saviano et al., 2019). To account for sustainability, the Quintuple Helix model recognizes that the fifth 'actor' of an innovation system is not a sector of performance but the 'environment', which creates overlapping institutional dynamics with the other actors (university, industry, government and society: Carayannis et al., 2012).

To our knowledge, there has not been a literature on the disadvantages of university interactions with organizations other than firms, equivalent to that of university-industry 
interactions. For our purposes, we are open to identify the same kind of conflicts with other types of stakeholders.

\subsection{University-industry interaction: neutral views?}

The typical paper on university-industry interaction takes its benefits for granted and cares about its promoting factors. Some of these influences apply to both universities and firms: managerial practices conducive to clear proprietary benefit (Barnes et al., 2002; Leischnig and Geigenmüller, 2018), shared norms and cognitive frameworks (Kalantaridis et al., 2017), geographical proximity -be it unimportant (Vedovello, 1997; Fischer et al., 2018), or important (Broström, 2010; Giunta et al., 2016)-, social capital (Al-Tabbaa and Ankrah, 2018), the stage of the interaction process (initiation or management: Goel et al., 2017), etc. Some aspects focus on universities: sociodemographic characteristics of academic researchers such as age and academic status (D'Este and Patel, 2007), psychological motivations for university-industry research (Azagra-Caro et al., 2008; Huszár et al., 2016) or education (Orazbayeva et al., 2019), the presence of successful project leaders (Takanashi and Lee, 2019), the quality of the university and radicalness of innovation (Tang et al., 2019), etc. Some other reasons refer to characteristics of the firms, such as the choice between exploitation and exploration, and absorptive capacity (Fernández-Esquinas et al., 2016), or the degree of continuity of their relations (Belderbos et al., 2015). Some causes refer to context and economic conditions like sectoral characteristics (de Moraes Silva et al., 2018), phase of the economic cycle (Azagra-Caro et al., 2019), access to government subsidies (Scandura, 2016), to business funding (Yegros-Yegros et al., 2016), etc.

This research path improves understanding of the processes leading to universityindustry interaction. In general, it does not recommend promoting that interaction, but how to do it if wanted. Hence, it does not take sides explicitly -just appears to be neutral. However, the fact that it accepts the prevailing discourse and its motivation is to identify the benefits of university-industry interaction may question this neutrality. Implicitly, one could say that it is legitimising the promotion of university-industry interaction. We are moving towards more critical perspectives in the next section. 


\subsection{Disadvantages of university-industry interaction and a typology of conflicts}

So far, we have discussed positive views about university-industry interaction. Critiques challenging this idealised view of what can be considered 'academic capitalism' (Slaughter et al., 2004) have been numerous. The academic reward system, based on the importance of scientific findings, is enough to guarantee a continuous flux of useful knowledge (David et al., 1992; Partha and David, 1994). The intromission of external stakeholders with their own private agendas may do nothing for the welfare of faculty members (Bozeman and Gaughan, 2011). Companies will tend to ask for shortterm, value-in-hand deliverables, which are at odds with fundamental understanding of nature and breakthrough discoveries. In the health sector, conscientious researchers find it hard to target industrial and clinical impact at the same time (Azagra-Caro and Llopis, 2018). Pharmaceutical companies try to influence professionals at every stage of their careers (Lieb and Koch, 2013). Industrial sponsorship in biomedical research is associated to more pro-industry conclusions, restrictions on publications and data sharing (Bekelman et al., 2003). Corporations will try to retain the property of the results, thus obscuring academic contributions to open science. Academics involved in contacts with firms will devote less time to teaching and publishing, endangering their performance in those domains (Banal-Estañol et al., 2015; McClure and Teitelbaum, 2016). They may even bias their results to please their private sponsors (Chiles et al., 2018), or use postdocs as visible boundary spanners, to safeguard their image (Johnson, 2018). Long standing university-industry interaction can lead to less valuable science-based innovations because of the inertia of these relationships, that cause both partners not to be aware of better existing technical solutions (Meyer-Krahmer and Schmoch, 1998). At disaggregate firm or firm project level, there does not seem to be a clear relation between innovation and cooperation with public research organisations (Guzzini and Iacobucci, 2017; Pennacchio et al., 2018). University-industry interaction may cause national and regional imbalances, since local interactions occur only where firms have high absorptive capacity (Azagra-Caro et al., 2010; 2013), and research excellence is necessary but not sufficient to strike regional impact (Bonaccorsi, 2017). Supranational policy action can rarely empathise with the actual local challenges faced by universities and firms (Marques et al., 2019). Actors highlight beneficial outcomes accruing to individual 
organisations rather than the societal benefits that are often cited as justifying government sponsorship (Ankrah et al., 2013).

Therefore, studies about university-industry interaction have exposed many of its potential conflicts. ${ }^{1}$ However, typologies of those conflicts are scarce. Campbell and Slaughter's (1999) typology of university-industry interaction conflicts is one of the most comprehensive. The authors distinguish between conflicts of interest, commitment and equity. We can summarise their respective meaning as dangers to the public service, lack of reporting to the academic organization and academic promotion based on relationships with industry. We will loosely use this typology to organise the empirical evidence.

\section{Methods}

Our corpus is composed of the novels that were concurrent winners of the Locus, Nebula and Hugo Awards, plus Frank Herbert's Dune ${ }^{2}$. We take these to be the mostrepresentative texts, inasmuch as a triple-awardee embodies wide critical and popular acclaim. The former prizes are the three most prestigious awards in the science fiction community, together covering the views of both experts and the public. The Locus Awards are conferred by the science fiction and fantasy stance magazine Locus (based in Oakland, CA), selecting winners via a readers' poll. The Nebula Awards are given by the Science Fiction and Fantasy Writers of America (SFWA); nominees and winners are chosen by published authors who are members of the association. The Hugo Awards are organized by the World Science Fiction Society; awardees are chosen by attending

\footnotetext{
${ }^{1}$ Some sort of synthesis has underscored that benefits and costs of university-industry interaction are undeniable, so the question is how to overcome the barriers that prevent successful interaction (Barnes et al., 2002; Bruneel et al., 2010; Bjursell and Engström, 2019; Kunttu and Neuvo, 2019). Another line of synthesis differentiates between types of interactions (D'Este and Patel, 2007), grouped in two broad types: university-industry commercialization and academic engagement (Perkmann et al., 2013). The former would comprise interaction mechanisms like patents and spin-off companies, whereas the latter would rely on others like joint R\&D, exchange and mobility of researchers, informal connections, etc. Academic commercialisation would therefore gather the most polemic aspects of interaction with firms, and would be less recommendable than academic engagement -a more accommodated way for faculty members to continue with their academic standards and serve practical means at the same time. Hence, both syntheses establish that university-industry interaction is not inherently bad, but has disadvantages that, properly managed, can turn into advantages. However, under the lens of the 'striving universities' approach, the fact that faculty can overcome the conflicts of involvement with industry is trivial: it hides that the cost is resignation, free time consumption and energy deprivation, not intrinsic motivation, and that only the auspices of a neoliberal ideology can justify that (Gonzales et al., 2014).

2 The inclusion of Dune, winner of two prizes only (Nebula and Hugo) obeys to its being the world's bestselling science fiction novel, which systematically makes it to the top in science fiction recommendation lists.
} 
members of the annual World Science Fiction Convention. Table 1 compiles the information.

There are 15 books, ranging from 1966 to 2013. New Wave science fiction is dominant, whereas contemporary subgenres such as steampunk are rare (Basset el al., 2013; Hrotic, 2014). The works have 14 authors, since one of them repeated the triplet (Connie Willis). They are all Anglo-Saxon, as a natural consequence of the three prizes being for English language books. 10 authors are men and 4 are women, which reflects the overrepresentation of males in the science fiction genre (Thelwall, 2017).

We analysed their contents as follows: Laura and Pedro split and read the books, produced fiches and extracted literal quotations. Joaquín read the summaries and other complementary information from online sources and discussed with Laura and Pedro whether the books provided evidence regarding university-industry interaction and how to classify it. 
Table 1. Joint winners of the Locus, Nebula and Hugo Awards

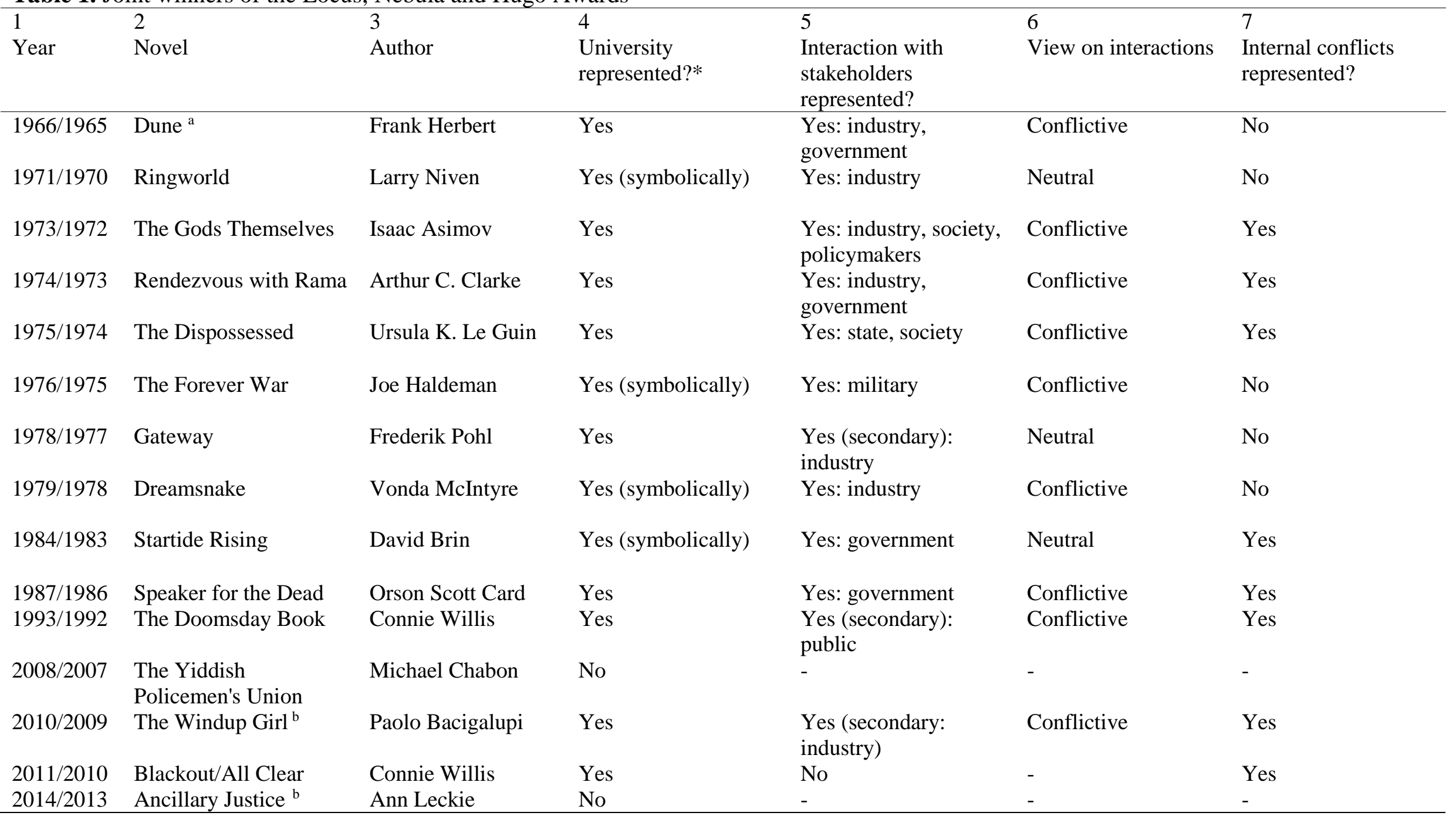

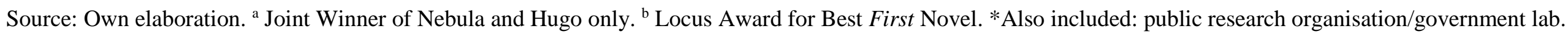


We found university represented in most of the works (Column 4). Of course, our methodological choices matter: First, we equated public research organisations (also known as government labs) with universities, since they experience similar conflicts from interaction with industry (Arza, 2010). Second, we included not only the often explicit but also the occasional symbolic representations of university, e.g. organized explorers (Ringworld) or medical bodies (Dreamsnake).

Debates about interaction with industry and other stakeholders were represented almost as often as university (Column 5). Following the literature on multiple stakeholders (see section 2.2), we included sectors other than industry: government/state, society/public, military (Carayannis and Campbell, 2009's Quadruple Helix Model loosely inspired labelling the sectors). Ex-post, we ratified this choice since the views on interaction were indistinguishable regardless of the type of stakeholder, as the results section will make clear: the narratives seem to have chosen industry or other sectors for coherence with the plot, not because of clearly distinctive conflicts with university. However, we have excluded debates without an organizational perspective, e.g. conflicts between the public and the private good, or between science and technology. We have also excluded critiques to corporate science, when they involved no interaction with university, even if the type of conflicts were similar, e.g. the lack of freedom of the industrial researcher, or the sacrifice of ethics for money.

In Column 5 we also specify whether the representation of the interaction is secondary to the plot (if not specified, it is most important). It means that the plot does not rely on it, usually because university characters are not protagonists. We realised this was an important distinction, because of a temporary pattern: the topic becomes less important as time goes by. We will later develop this issue.

We qualified the views on interactions as positive, conflictive or neutral, but we could never apply the category 'positive' -that is already a surprising result (Column 6). We will develop these views in detail in the next section. Let us indicate first that the representation of internal conflicts in the university system is the norm rather than the exception, e.g. the pursuit of scientific prestige at the expense of the public service and the quest for truth is a recurrent topic. We included Column 7 in Table 1 to show that most works do not depict a Manichean dichotomy between the purity of the university and the dirtiness of industry, but are critical to both worlds. However, internal conflicts are not the target of our study, so we do not develop them unless indispensable. 


\section{Results}

\subsection{Predominantly negative view of university interactions}

In 12 out of the 15 books there are representations of relationships between university and other stakeholders, i.e. the topic has been prevalent for influential science fiction works. The representation is conflictive in 9 out of those 12 books, it is neutral in 3 and it is never positive.

Time seems to play a role: 10 books are from the $60 \mathrm{~s}-80 \mathrm{~s}$, and in almost all of them (9) the topic is core to the plot. 5 books are from the $90 \mathrm{~s}-00 \mathrm{~s}$, and in all of them the topic is not so important (The Doomsday Book and The Windup Girl) or it is not represented (The Yiddish Policemen's Union, Blackout/All Clear and Ancillary Justice). We can take this as a symptom that initial fears against excessive intromission of third parties in academic research agendas have given rise to milder views or disaffection to the subject. ${ }^{3}$ We tentatively attribute it to changes in the public opinion after the 1970s Oil Crises to promote a more active role of universities in economic development. A milestone was the passing of the Bayh-Dole Act by the US Congress in 1980 (Mowery et al., 2001), which facilitated commercialisation of academic patents. Long-term effects of this change of mentality may have added to the current prevalence of positive attitudes towards university-industry interaction among scholars, at least in the literature on multiple stakeholders of research (see section 2.2). In any case, Sci-Fi authors have not replaced scepticism by a positive depiction of university-industry interaction. We now turn to this negative or, at most, neutral representations in the following sections.

\subsection{Neutrality? Academics teaching and consulting for industry}

The closest depiction of harmony between the worlds of science and market appears in Gateway. This novel encloses an underlying acceptance of their relationships as in the works referred in section 2.2. Here, humans find an extra-terrestrial technology that allows for space travel. Success is not guaranteed and space travellers face a chance of

\footnotetext{
${ }^{3}$ Connie Willis provides the best example: in her two prized novels, university researchers get trapped in the past. However, whereas in The Doomsday Book, written in the 1990s, this is due to interaction with the public, in Blackout/All Clear, written in the 2010s, this is due to the internal dynamics of the academic profession. Blackout/All Clear is also the only book in the list that includes representations of university, but not of interaction with stakeholders.
} 
dying, but also of getting new artefacts and knowledge. The Gateway Corporation is the publicly sanctioned monopoly in charge for the use of the alien technology, and it hires college professors referred to as the Corporation Science Research Division or the $R \& D$ people: they teach travellers about the space, and analyse the possible discoveries. This is very secondary in the plot, but we highlight it as one of the few non-critical approaches to university-industry interaction. The story narrates how academics work for industry with neutrality, without any obvious clues to judge its advantages or disadvantages. ${ }^{4}$

\subsection{Conflict of interest with the public service (a): threats to sustainability}

This category echoes most of the disadvantages of university-industry interaction (section 2.4): reduced research quality, knowledge diffusion, innovation and societal impact. Science fiction represents these drawbacks with dramatic metaphors on dangers to sustainability, from natural resource deprivation to mass destruction and end of planets. Hence, our evidence challenges the literature on multiple stakeholders of research, which finds university-society interaction and sustainability compatible (section 2.2).

This sub-section is also the more populated with examples, starting with the oldest novel in the sample: Dune. It narrates the story of a galactic economy based on the traffic of melange, a spice produced only in one planet, Arrakis, inhabited by the Fremen. The Emperor granted the non-local Harkonnen family the management of Arrakis. Kynes, an Imperial Planetologist who conducts research in Arrakis, is critical to the way the Harkonnens have exploited it for their own benefit and in detriment to the Fremen. He oversees the transition between the outgoing Harkonnens and another family, the Atreides, who have been granted domain over the planet. Duke Leto Atreides then gives Kynes permission to study the spice:

I don't care if you study the spice as long as I share what you discover [...]. The Harkonnens discouraged investigation of the spice, didn't they?

\footnotetext{
${ }^{4}$ However, in the book, the only existing science is science at the service of the economy, which may contain an implicit critique, but too subtle for us to be conclusive.
} 
The Harkonnens had actually prevented Kynes' research in the past, and the Emperor himself does not seem to support either. In fact, the Emperor has allowed this transaction between families in connivance with the Harkonnens, in order to set a trap to the Atreides -a representation of a conglomerate of industrial-government interests. The Harkonnens, back in charge, target and eventually succeed in killing Leto Atreides and Kynes:

-Have the Man [Kynes] killed.

-M'Lord! Kynes is the Imperial Planetologist, His Majesty's own

ser-

-Make it look like an accident.

The careless exploitation of natural resources in the planet restarts.

The Gods Themselves tells a similar threat, this time to planet Earth. Radiochemist Frederick Hallam develops a cheap, clean, and apparently endless source of energy: the "Pump". He becomes an academic entrepreneur (Bercovitz and Feldman, 2008; Guo et al., 2019) that controls the scientific world and runs the private Pump Station facilities. Physicist Peter Lamont and archaeologist and linguist Mike Bronowski, working at university, discover that the Pump increases the strong nuclear force inside the Sun, bound to eventually explode. Hallam is totally closed to accepting this, and Lamont attempts to demonstrate it to a senator, who refuses his request:

Young man, my powers, on paper, are enormous, but I can only succeed when the public is willing to let me. It is a mistake [...] to suppose that the public wants [...] the environment protected or their lives saved and that they will be grateful to any idealist who will fight for such ends. What the public wants is their own individual comfort... You have a theory but a theory by itself is meaningless.

The moral is that everyone is driven by self-interest: the public, who does not want to believe in inconvenient truths (such as the Pump, which provides free energy to 
everyone, but could potentially be harmful); as well as politicians, who do not want to risk their reputation.

In the words of another character, ex-academic physicist Denison, simultaneously colleague and rival of Hallam:

The easiest way to solve a problem is to deny it exists.

We find similar examples in Rendezvous with Rama. An alien starship named Rama enters the Solar System. Survey vessel Endeavour is sent to explore and study it. A committee of scientists and representatives of the United Planets (Mercury, Earth, Luna, Ganymede, Titan and Triton), based on the moon, monitors events and gives feedback. Various conflicts dominate the dynamics between both groups, in the form of impossible problem-solving requests, and constant demands of cost-benefit analysis, from politicians to scientists.

However, the ultimate challenge for scientific quest is that from Mercury, who embodies the concept of "technological barbarism" (in the words of one character): with vast engineering skills, Hermians (natives from Mercury) are the Solar System top exporters of metal, metal manufactures and energy. They are used to living in "survival mode" due to the brutal conditions of their planet: isolated, and constantly weighing the risks against the benefits. The citizens from all the other planets, on the other hand, have a "thrive mindset": they value art, and lean towards a respectful pursuit of knowledge that takes into account others' needs as well as one's own. It is easy to see in this dichotomy between Mercury and the others a representation of the conflict between challenge-driven and frontier research. Hermians conclude that the risk Rama poses is not worth the potential gains, so they unilaterally launch a missile to destroy it, but one of the astronauts neutralises the rocket. The mission commander puts it this way:

The human race has to live with its conscience. Whatever the

Hermians argue, survival is not everything.

The threat is even more palpable when the boundaries between the state and the military blur. In The Forever War, there is a war between Earth and Taurus. National and international governments orient their economies towards armed fighting -science at the forefront. The United Nations recruit the most brilliant college students, including the main character, William Mandella, for their elite battle forces. We see here a parallel 
with reports of university students' pro-industry bias after receiving gifts by companies (Lieb and Koch, 2013). The war lasts for hundreds of years, and Mandella finally discovers its futility: it started by accident, but Earth's public-private forces in power made it look like the result of Taurans deliberate hostility.

We find a similar example in The Doomsday Book, in which time-travel is an ordinary practice for historians at the University of Oxford, until some sceptics seem to think that it has something to do with a current epidemic. Gilchrist, Acting Head of the History Faculty, closes the laboratory, even though there is no scientific basis for that belief:

Our position in the community [...] depends on maintaining the goodwill of the townspeople. I felt it important to calm the public's fears by closing the laboratory until the sequencing arrives. If it indicates that the virus is from South Carolina, then of course the laboratory will be reopened immediately.

There seems to be a dependence on public opinion and approval, even though their fear is without foundation..$^{5}$ Keeping the public content is a priority, even to the expense of scientific endeavor, and the safety of the scientists themselves: with the decision to close the laboratory, Gilchrist puts in danger the life of the main character, Kivrin, another scientist who has travelled to the past and is stranded there.

In The Windup Girl, people die of starvation worldwide. Large corporations control food supply and are responsible for plagues, depletion of natural resources and subsequent food scarcity that come with their engineered products. However, Thailand has managed to resist subjugation by maintaining its own reserve of seeds and restricting imports, which need to pass tight inspection. Companies such as AgriGen, seek to find and seize the Thai seedbank, a sort of public laboratory, so that the country is forced to buy and depend on their products (a situation that may resemble conflicts raised by Chiles et al., 2018).

\footnotetext{
${ }^{5}$ A researcher opposed to Gilchrist ironizes against him with a highly topical issue at the time of writing this paper: "There has been 'considerable public concern', as you call it, that the virus was caused by liberal immigration laws [...]. Do you intend to secede from the EC as well?" (italics are ours). It could have been written today in reference to Brexit.
} 
A secondary character, Gibbons, is in charge of the seedbank, where he conducts research on food processing. He used to work for AgriGen but moved to the public sector, renouncing a higher salary and access to better resources in favour of more intellectually challenging tasks. These motivations are already suggesting that potential tensions of university-industry interaction may arise because of the different incentives of each sector. More explicitly, when a new plague threatens the seedbank, Gibbons helps one of the protagonists to find that AgriGen has caused the plague, so he utterly engages with the public sector (even if he usually acts with ironic distance).

Notice that every kind of stakeholder can be a source of conflict: not only industry, despite the ample literature on university-industry interaction vis-à-vis other university interactions; and despite the favourable views on interactions with multiple stakeholders present in the literature on knowledge transfer policies (more specifically: if there is ever someone to blame, industry is the first suspect: see Saviani et al., 2019). In the novels analysed, only The Windup Girl focuses on industry; in most of them, industry forms an ensemble with government, society or policymakers (Dune, The Gods Themselves, Rendezvouz with Rama); in others, industry does not cause the conflict, but other sectors like the military or the public (The Forever War, The Doomsday Book). Hence, for science fiction novels industry can be as threatening for sustainability as any other stakeholders.

\subsection{Conflict of interest with the public service (b): keeping ownership of ideas}

The most important issue within the debate about the pros and cons of academic commercialization is probably the enforcement of intellectual property rights at university. Among other dilemmas, some consider academic patenting as conducive to more influential research (Azoulay et al., 2009), whereas others find it detrimental, at least after a threshold, not only to research quality but also to engagement in several interaction channels (Crespi et al., 2011). Although we found no explicit mention to legal mechanisms in our sample of books, some use the concept of intellectual property protection as dramatic material.

For instance, in The Dispossessed, physicist Shevek accepts a position as a professor at an Urrasti university, in the capitalist state of A-Io. However, Shevek finds this state is 
closer to a "private", profit-maximising institution (although it is supposed to be democratic, it is not), as the government monetizes and selfishly profits from publiclyfunded research. What Shevek wants is to make his knowledge available to everyone: knowledge belongs to the people; not the government, not a group of elite individuals, but everyone.

I came here from Anarres because I thought that here I could do the work and publish it. I didn't understand that here an idea is a property of the State. I don't work for a State. I can't take the money and the things they give me. I want to get out [...]. I was to be kept from the populace, to live among scholars and the rich. Not to see the poor. Not to see anything ugly... There I was to be happy and do my work, the work I could not do on Anarres. And when it was done I was to give it to them, so they could threaten you with it.

In Dreamsnake, the main character, Snake, is a member of the Healers, a community organized like academics: their mission is to pursue and apply knowledge for the sake of practising medicine. Mentors guide students until they are worth of holding the title of Healers; and Healers can lose their title in case of misbehaviour, as judged by their peers. The novel poses a curious situation of technological lock-in (as described by MeyerKrahmer and Schmoch, 1998): Healers use 'dreamsnakes', an extra-terrestrial species of snakes whose poison relieves pain, but do not know how to breed them. That is to say, Healers possess applied knowledge that guarantees usability of resources, but not the basic knowledge for ensuring their constant supply.

Because of a sort of imprudence, Snake's dreamsnake dies. She needs to replace it in order not to lose her Healer title, and she has two possibilities, but faces obstacles due to ownership restrictions:

- Inhabitants of Central City, notable traders, get new dreamsnakes from commercial exchange with the Otherworlders, the extra-terrestrial race that breeds them. Central Citizens have not made public how to contact 
Otherworlders, keep dreamsnakes for their own consumption and are particularly reluctant to share dreamsnakes with Snake and the Healers, who use them for the public good. One can see here a metaphor of capitalism preventing knowledge diffusion.

- North, a researcher-like individual who hates Healers, finds the way to breed dreamsnakes. He keeps the secret for his own benefit, since he gets the adoration of followers who have become addicted to the drug secreted by dreamsnakes, and he even tries to kill Snake. This could be a representation of the 'entrepreneurial' scientist, separated from the disinterested academic community.

Unlike in The Dispossessed, in Dreamsnake there are mentions to a formal retention instrument: Central Citizens live in a walled city, and partly they control who can enter the city and therefore access to their knowledge (and trade networks). North in turn lives in an isolated area, which is not easily accessible, within what seems to be a spaceship that crashed on Earth. In fact we could see these physical barriers as representations of the closure of knowledge through intellectual property rights (actually, there are historical examples of the link between physical enclosure and enforcement of intellectual property rights: see Boyle, 2017). Hence, Central Citizens and North have put in place some sort of mechanism to retain ownership of basic knowledge for commercial interests. $^{6}$

\subsection{Conflict of commitment (I): non-disclosure of information as a problem}

Property right enforcement and non-disclosure of information are similar inasmuch they restrict knowledge diffusion. However, the former restricts open access through legal means and the latter does so through secrecy -this sub-section covers this aspect of the problem.

\footnotetext{
${ }^{6}$ There are explicit mentions to knowledge diffusion in Dreamsnake. The main character reflects upon how network fragmentation hinders knowledge diffusion.
} 
Yet another character from Dune (see section 4.2) exemplifies the corruption of scientists who serve private interests. Doctor Yueh is a physician from a Suk School, which imposes Imperial Conditioning -a sort of unbreakable Hippocratic Oath that renders them incapable of inflicting harm. The Harkonnens kidnap Yueh's wife, coercing him into betraying the Atreides, whom he serves. Yueh, a wise and good man of science, is not reliable any longer for his 'organization', due to the external pressures of 'industrial' stakeholders (represented by the Harkonnen).

Speaker for the Dead covers another angle of secrecy: one motivated by ethical concerns. In this novel, a family of xenologers analyse the second alien species ever found by humans, the Pequeninos. Pequeninos suffer disease and hunger, and the xenologers can help them, but an Earth government body, the Starways Congress, forbids it. Humans unduly caused the extinction of the first alien race they encountered, and their sense of guilt has become so strong as to ban sharing science and technology with extraterrestrials, to protect the latter from any unintended harm. Hence, although external imposition of secrecy endangers the free pursuit of science, this is not at odds with sustainability and life, unlike in other novels. However, the main character, Ender, ally of the xenologists, suspects that the Starways Congress overprotects other species interestedly:

At that moment Ender saw clearly that the rules governing human contact with the piggies [another name for Pequeninos] did not really function to protect the piggies at all. They functioned to guarantee human superiority and power [...]. Why are we so anxious to keep them from any influence from our culture? It isn't just in the interest of science. It isn't just good xenological procedure. Remember, please, that our discovery of the ansible, of starflight, of partial gravity control, even of the weapon we used to destroy the buggers [the first, extinguished, alien race] all of them came as a direct result of our contact with the buggers [...] in only a few generations, we took their machines, surpassed 
them, and destroyed them [...]-we're afraid the piggies will do the same to us.

Because the reader sympathises with Ender as the protagonist, it is difficult not to adopt his point of view and feel that unethical concerns counterbalance ethical ones, so the notion that secrecy is detrimental to science prevails. The ambiguity is higher in the next set of novels.

\subsection{Conflict of commitment (II): non-disclosure of information as an acceptable evil}

Ringworld provides a neutral piece of evidence regarding non-disclosure of information (neither positive, nor negative). University and industry are represented metaphorically by the two main characters of the novel: Louis $\mathrm{Wu}$, an Earth adventurer whose goal is to pursue knowledge for its own sake; and Nessus, from the alien race of the Pupeteers, rulers of a galactic mercantile empire. The latter hires the former to explore a space structure called Ringworld, and promises the spaceship in which both travel as payment, establishing a pecuniary reward that is reminiscent of a universityindustry contract. One interesting point for this research is that Nessus recruits two other crewmembers, Speaker (an alien from the Kzin race) and Teela (a particularly lucky Earth Human). During the expedition, Nessus unveils that Puppeteers have genetically engineered Kzin and lucky Humans like Teela to achieve results that are amenable to their interests. On the one hand, the crewmembers get angry, but on the other hand Nessus's revelations occur because of comradeship out of having lived adventures together. This suggests that communication and trust may alleviate the tension raised by secrecy, as in the case of university-industry interaction.

The final resolution adds an extra layer of complexity and is even more relevant for our purpose. When the mission finishes, on the way back to their planets, Louis and Speaker decide not to disclose the Pupeteers' manipulation of Humans and Kzinti, because it would be too disturbing for their races, putting peace at risk and potentially leading to their annihilation, since Pupeteers are more technologically capable. This indicates that state pacts are necessary to cope with the advantages and disadvantages of inter-institutional relationships, and that individuals can micro-manage unresolved conflicts. 
A somewhat similar ambiguity is present in Startide Rising. Here, the Council of the Five Galaxies regulates the coexistence of most known races, in unstable equilibrium. The Council relies on the Library, an aeons-old institution that (supposedly) stores all available knowledge and makes it publicly accessible. Most species use it to build further advances. Earthlings, on the other hand, prefer research-based development instead, which sets them apart. Humans represent then the closest depiction of university endeavor in this fictional universe.

In this context, the Earth's government sends spaceship Streaker to explore the galaxy, i.e. a possible representation of university researchers. Its crew finds evidence of the existence of the Progenitors, the mythical creators of life: the location of a derelict fleet, some artifacts and an alien body. The Streaker's crew mission becomes to deliver this information to their government, but other races that want to take possession of the secret soon pursue them, and the crew tries to escape. They could 'sell' their secret to some races in exchange for their life, but they run away and fight if necessary for loyalty to their government. Hence, this represents an act of non-disclosure of information for nationalistic reasons: the secret belongs to the 'heroes"' homeland, not to others. ${ }^{7}$ As one of the members of the crew puts it:

Our discovery will be given only to the Galactic Institutes, and only by our Terragens Council leaders themselves.

Thus, the crew does not completely deny the convenience of submitting the secret to the Library Institute to make it publicly available, but concludes that the decision corresponds to the Terran government. Their commitment to waiting to share the information instead of broadcasting it immediately to the Library is actually quite understandable, and seems to obey other than purely selfish reasons. Throughout the novel, it is repeatedly established that the Library's records have been manipulated, which renders this repository of knowledge unreliable: thus another source of ambiguity is introduced. It could be argued that, again, non-disclosure of information is a better option, justified by lack of trust in institutions that are located in less reliable contexts.

\footnotetext{
${ }^{7}$ The novel does not offer particular reasons to despise other races, but the fact that the main characters are humans (like, most likely, the reader), humans are the most curious race in the galaxy and they have been discoverers in a 'quest for truth' predispose the reader to take sides with them.
} 
Overall, Startide Rising shares with Ringworld a neutral view of universities' nondisclosure of information with others. It does not lead to clear advantages, but may avoid worst-case scenarios.

\subsection{Conflict of equity: lower promotion of 'disengaged' academics}

Should scientists be able to research whatever they are interested in, or should society dictate that according to its own needs? Before moving to Urras, in The Dispossessed (see section 4.4), Shevek lives in Anarres, where he is frowned at for not focusing on the problems his society considers more important. He joins the university to develop his theory, but Sabul, a jealous superior, blocks his work. He is accused of putting his personal desires and intellectual interests before society's needs. He loses his job at the university, effectively being forced to perform agricultural labour, instead of working on his research. Sabul explains it to Shevek:

What worked against you was a combination of things. The abstruse, irrelevant nature of the research you've done these last several years. Plus a certain feeling, not necessarily justified, but existing among many student and teaching members of the Institute, that your teaching and behaviour both reflect a certain disaffection, a degree of privatism, of non-altruism.

The Doomsday Book provides another piece of evidence. As mentioned in section 4.2, the Oxford History Department customarily sends students and researchers to the past, to do field work. Periods have a danger rating (out of ten) and the riskiest ones are off-limits. This has traditionally been the case for the medieval period (which has a rating of 10): no one has been allowed to travel to the Medieval Ages because of the potential risks. Gilchrist, Acting Head of the History Faculty, coaxes authorities to open the fourteenth century, in the hope that he will score a point by orchestrating this groundbreaking operation, and sends Kivrin (an enthusiastic History student) to study medieval customs. He even skips several protocols that would ensure the student's safety to speed things up. However, when problems arise, the present suffers an epidemic and the public blames time travel for that, despite the lack of convincing proofs (see section 4.2), Gilchrist refuses to take any responsibility and blames others instead. Symbolically, once 
the evaluation criteria take into account societal impact and opinion, Kivrin is left out of academia (literally left out: she remains isolated in the past). As a researcher, she is abandoned by her institution when her investigation is deemed to run counter to society's interest.

\section{Conclusions}

The influence between literary representation and society is reciprocal: fictional depictions of scientific research reflect, at least to some extent, society's opinions and fears. At the same time, literature has the power to shape public opinion with positive or negative representation of social phenomena. In this paper, we merge university-industry interaction studies with the literature on representations of science in popular culture. By doing so, we expect to have contributed to studies on university-industry interaction and frames for STI policy by signalling that the predominant popular view of universitysociety interactions is negative, at least in our sample, despite the prevalent academic and policy support. This suggests that policymakers have not focused on the relevance of discourse for legitimising action (McCloskey, 2002). Of course, one limitation of our study is the small number of books analysed, but their literary prestige and the strong, two-way connection between science and science fiction (Miller and Bennet, 2008; Kirby, 2010; Basset et al., 2013) suggests that there is no smoke without fire.

Certainly, there has been a decline in the importance and frequency of attacks from science fiction to university engagement with multiple stakeholders. Maybe public opinion is slowly changing towards a neutral attitude than may eventually become favourable towards university interactions. However, we have not found any fictional narrative showing clearly that these interactions are key to solve societal problems. A possible policy recommendation would be to fund literary competitions with that target or promote the participation of writers in foresight exercises, like France is doing nowadays for imagining military scenarios ${ }^{8}$. A contrasting hypothesis is that public perceptions of science and universities have become more cynical, meaning that the narrative of the romantic scientist who merely cares about the pursuit of truth is no longer

\footnotetext{
8 'The French Army is hiring science fiction writers to imagine future threats': https://www.theverge.com/2019/7/24/20708432/france-military-science-fiction-writers-red-team [last access: 17/9/2019].
} 
used in fiction because it is no longer believable. In this scenario, the portrayal of university interactions as neutral is merely because it is no longer problematic to assume that science and universities are at the service of economic or political interests.

Our study provides some additional insights when it breaks down the different facets of university interactions with multiple stakeholders: conflicts of interest, commitment and equity.

- Research on university-industry interaction has provided many examples of its advantages, but also some about its conflicts of interest with the public service. Current framings for STI policy have stressed that universities also interact with non-industrial stakeholders and contribute to the sustainability of socioeconomic systems (the 'productive interactions', 'societal impact', 'RRI', 'transformative change', 'quadruple/quintuple helix' approaches), but have rarely discussed unintended consequences of university-society interaction. Science fiction novels provide extensive evidence of stakeholders other than industry, and of how conflicts of interest with the public service threaten sustainability. Hence, we suggest that current framings for STI policy incorporate elements of critical studies of university-industry interaction to avoid barriers to sustainability due to university interaction with multiple stakeholders.

- The literature on university-industry interaction and current framings for STI policy give varied importance to conflicts of commitment at universities, but they concur to consider that non-disclosure of information is not desirable. Surprisingly, science fiction novels illustrate two acceptable reasons for nondisclosure of information: nationalism and state pacts. When universities open foreign access to information that can put national security in danger, or when universities agree with companies and government that keeping a secret may 
benefit social cohesion, this may legitimise restrictive measures. These propositions have not been properly analysed, so science fiction is a useful tool to open research avenues.

- Conflicts of equity, namely the downgrading of 'disengaged' academics, have received scarce attention. The reason may be that most research systems still base academic promotion in scientific merit, so its replacement for application merit is not a big concern yet. However, knowledge transfer and diffusion are progressively included in the evaluation of merit, and may eventually gain more weight than scientific quality. The representation of university-society interaction in science fiction is particularly insightful to anticipate two reasons of conflict: pleasing the public opinion and punishment of non-altruism. Because both are heavily subjective reasons, Sci-Fi novels alert about the need to establish clear criteria for the inclusion of interaction with society in the promotion of academic researchers, especially if it becomes as important or more than scientific merit.

Our aim is also to have contributed to the literature on representations of science in popular culture. Here the usual focus has been the isolated public researchers, and we have extended the inquiry to their interactions with industry and other stakeholders. In addition to this theoretical contribution, our findings posit a new idea: depictions of the isolated researcher tend to be ambiguous, and our own expectation was to find an equally uncertain representation of academic interactions. However, we found an almost unambiguous, negative representation. The only exception is conflicts of commitment due to secrecy, which are sometimes characterised as neutral, as aforementioned. We believe our study opens the question of why the ambivalent portrayal of scientists in isolation becomes almost univalent when confronted to stakeholders.

A negative view of university-industry/society interaction may be due to political ideology. Although most political parties rarely argue against this interaction, there is a capitalist component in its promotion that left-wing ideologies could despise. In this 
sense, we may wonder whether left-wing writers populate science fiction and thus our choice of genre may have biased our findings. However, we have chosen three prestigious awards, and it is difficult to contend that all of them present the same ideological bias. Moreover, even though our sample includes feminists like Ursula K. LeGuin or Vonda McIntyre, it also incorporates Orson Scott Card, a public Republican supporter, opponent of homosexuality and same-sex marriage, and a practicing Mormon ${ }^{9}$. In any case, reality is sometimes more complex and ideological frontiers dilute: popular prizes like the Hugo alternate conservative and progressive decisions ${ }^{10}$, and there are ambivalent authors like Connie Willis, who sacrifice their strong Christian beliefs for the sake of a story ${ }^{11}$, or Frank Herbert, an environmentalist who earned part of his living writing speeches for Republican congressmen (Herbert, 2003). Of course, this is just anecdotic evidence, which future studies on the ideology of writers or the presence of university-industry interaction in other genres or manifestations of popular culture could approach.

\section{Acknowledgements}

The Spanish Ministry of Science, Innovation and Universities funded this research through Project CSO2016-79045-C2-2-R of the Spanish National R\&D\&I Plan. The CSIC funded Laura's stay at INGENIO that started the work through Aid JAEINT17_EX_0661 of the JAE Intro Programme. Attendants of our sessions at the 2018 Technology Transfer Society (T2S), 2019 University-Industry Interaction (UIIN), $13^{\text {th }}$ Science in Public (SiP) and the $3^{\text {rd }}$ Research Evaluation in the Social Sciences and Humanities (RESSH) Conferences gave substantial comments. Irene Monsonís Payá helped us during the research.

\footnotetext{
${ }^{9}$ https://en.wikipedia.org/wiki/Orson_Scott_Card\#Opinion, last access 3/3/2019.

10 https://www.realclearpolitics.com/articles/2015/08/30/mutiny at the hugo awards 127934.html [6/6/2019]

${ }^{11}$ In her words: 'I want always to be a writer, and if my religion is what has to go, so be it. The story is everything', in https://www.hourwolf.com/chats/willis.html [10/6/2019].
} 


\section{References}

Al-Tabbaa, O., \& Ankrah, S. (2018). 'Engineered' University- Industry Collaboration: A Social Capital Perspective. European Management Review.

Alberich, R., Miro-Julia, J., \& Rosselló, F. (2002). Marvel Universe looks almost like a real social network. arXiv preprint cond-mat/0202174.

Ankrah, S. N., Burgess, T. F., Grimshaw, P., \& Shaw, N. E. (2013). Asking both university and industry actors about their engagement in knowledge transfer: What single-group studies of motives omit. Technovation, 33(2-3), 50-65.

Archibugi, D. (2017). Blade Runner economics: Will innovation lead the economic recovery?. Research Policy, 46(3), 535-543.

Arza, V. (2010). Channels, benefits and risks of public-private interactions for knowledge transfer: conceptual framework inspired by Latin America. Science and Public Policy, 37(7), 473-484.

Audretsch, D. B., Lehmann, E. E., \& Wright, M. (2014). Technology transfer in a global economy. The Journal of Technology Transfer, 39(3), 301-312.

Audretsch, D. B., Lehmann, E. E., Paleari, S., \& Vismara, S. (2016). Entrepreneurial finance and technology transfer. The Journal of Technology Transfer, 41(1), 1-9.

Azagra-Caro, J. M., \& Consoli, D. (2016). Knowledge flows, the influence of national R\&D structure and the moderating role of public-private cooperation. The Journal of Technology Transfer, 41(1), 152-172.

Azagra-Caro, J. M., \& Llopis, O. (2018). Who do you care about? Scientists' personality traits and perceived impact on beneficiaries. $R \& D$ Management, 48(5), 566-579.

Azagra-Caro, J. M., Aznar-Marqez, J., \& Blanco, J. M. (2008). Interactive vs. non-interactive knowledge production by faculty members. Applied Economics, 40(10), 1289-1297.

Azagra-Caro, J. M., Carat, G., \& Pontikakis, D. (2010). Inclining the columns to make the temple look straight: a first glance at monetary indicators on university-industry cooperation. Research Evaluation, 19(2), 119-128.

Azagra-Caro, J. M., Fernández-Mesa, A., \& Robinson-García, N. (2018). 'Getting out of the closet': scientific authorship of literary fiction and knowledge transfer. The Journal of Technology Transfer, 130. 
Azagra-Caro, J. M., Pardo, R., \& Rama, R. (2014). Not searching, but finding: how innovation shapes perceptions about universities and public research organisations. The Journal of Technology Transfer, 39(3), 454-471.

Azagra-Caro, J. M., Pontikakis, D., \& Varga, A. (2013). Delocalization patterns in university-industry interaction: Evidence from the Sixth R\&D Framework Programme. European Planning Studies, 21(10), 1676-1701.

Azagra-Caro, J. M., Tijssen, R. J., Tur, E. M., \& Yegros-Yegros, A. (2019). University-industry scientific production and the Great Recession. Technological Forecasting and Social Change, 139, 210-220.

Azoulay, P., Ding, W., \& Stuart, T. (2009). The impact of academic patenting on the rate, quality and direction of (public) research output. The Journal of Industrial Economics, 57(4), 637-676.

Balconi, M., \& Laboranti, A. (2006). University-industry interactions in applied research: The case of microelectronics. Research Policy, 35(10), 1616-1630.

Banal-Estañol, A., Jofre-Bonet, M., \& Lawson, C. (2015). The double-edged sword of industry collaboration: Evidence from engineering academics in the UK. Research Policy, 44(6), 1160-1175.

Barnes, T., Pashby, I., \& Gibbons, A. (2002). Effective university-industry interaction: A multi-case evaluation of collaborative R\&D projects. European Management Journal, 20(3), 272-285.

Bassett, C., Steinmueller, E., \& Voss, G. (2013). Better made up: The mutual influence of science fiction and innovation. Nesta Work. Pap, 13(07).

Bekelman, J. E., Li, Y., \& Gross, C. P. (2003). Scope and impact of financial conflicts of interest in biomedical research: a systematic review. Jama, 289(4), 454-465.

Belderbos, R., Carree, M., Lokshin, B., \& Sastre, J. F. (2015). Inter-temporal patterns of R\&D collaboration and innovative performance. The Journal of Technology Transfer, 40(1), 123-137.

Bercovitz, J., \& Feldman, M. (2008). Academic entrepreneurs: Organizational change at the individual level. Organization science, 19(1), 69-89.

Bjursell, C., \& Engström, A. (2019). A Lewinian Approach to Managing Barriers to University-Industry Collaboration. Higher Education Policy, 32(1), 129-148.

Bonaccorsi, A. (2017). Addressing the disenchantment: universities and regional development in peripheral regions. Journal of Economic Policy Reform, 20(4), 293-320.

Bornmann, L. (2013). What is societal impact of research and how can it be assessed? A literature survey. Journal of the American Society for Information Science and Technology, 64(2), 217-233. 
Bowman, D. M., Hodge, G. A., \& Binks, P. (2007). Are we really the prey? Nanotechnology as science and science fiction. Bulletin of science, technology \& society, 27(6), 435-445.

Boyle, J. (2017). The second enclosure movement and the construction of the public domain. In Copyright Law (pp. 63-104). Routledge.

Bozeman, B., \& Gaughan, M. (2011). Job satisfaction among university faculty: Individual, work, and institutional determinants. The Journal of Higher Education, 82(2), 154-186.

Broström, A. (2010). Working with distant researchers-Distance and content in university-industry interaction. Research Policy, 39(10), 1311-1320.

Bruneel, J., d'Este, P., \& Salter, A. (2010). Investigating the factors that diminish the barriers to university-industry collaboration. Research policy, 39(7), 858-868.

Caiazza, R., Richardson, A., \& Audretsch, D. (2015). Knowledge effects on competitiveness: from firms to regional advantage. The Journal of Technology Transfer, 40(6), 899-909.

Campbell, T. I. D., \& Slaughter, S. (1999). Faculty and administrators' attitudes toward potential conflicts of interest, commitment, and equity in university-industry relationships. The Journal of Higher Education, 70(3), 309-352.

Carayannis, E. G., \& Campbell, D. F. (2009). 'Mode 3' and 'Quadruple Helix': toward a 21st century fractal innovation ecosystem. International Journal of Technology Management, 46(3-4), 201-234.

Carayannis, E. G., Barth, T. D., \& Campbell, D. F. (2012). The Quintuple Helix innovation model: global warming as a challenge and driver for innovation. Journal of innovation and entrepreneurship, 1(1), 2.

Chiles, R. M., Glenna, L., Sharma, A., Catchmark, J., Azzara, C. D., \& Maretzki, A. (2018). Agri-food firms, universities, and corporate social responsibility: what's in the public interest?. Renewable Agriculture and Food Systems, 1-11.

Clark, B. R. (1998). Creating Entrepreneurial Universities: Organizational Pathways of Transformation. Issues in Higher Education. Elsevier.

Cooke, P. (2018). Responsible research and innovation? From FinTech's 'flash crash'at Cermak to digitech's Willow Campus and Quayside. European Planning Studies, 1-18.

Crespi, G., D’Este, P., Fontana, R., \& Geuna, A. (2011). The impact of academic patenting on university research and its transfer. Research policy, 40(1), 55-68.

D'Este, P., \& Patel, P. (2007). University-industry linkages in the UK: What are the factors underlying the variety of interactions with industry?. Research policy, 36(9), 1295-1313. 
David, P. A., Mowery, D., \& Steinmueller, W. E. (1992). Analysing the economic payoffs from basic research. Economics of innovation and New Technology, 2(1), 73-90.

De Cock, C. (2000). Essal: Reflections on fiction, representation, and organization studies: An essay with special reference to the work of Jorge Luis Borges. Organization Studies, 21(3), 589-609.

de Moraes Silva, D. R., Furtado, A. T., \& Vonortas, N. S. (2018). University-industry R\&D cooperation in Brazil: a sectoral approach. The Journal of Technology Transfer, 43(2), 285-315.

Etzkowitz, H. (1998). The norms of entrepreneurial science: cognitive effects of the new universityindustry linkages. Research policy, 27(8), 823-833.

Etzkowitz, H., \& Leydesdorff, L. (2000). The dynamics of innovation: from National Systems and "Mode 2" to a Triple Helix of university-industry-government relations. Research policy, 29(2), 109-123.

Fähnrich, B. (2017). Science diplomacy: Investigating the perspective of scholars on politics-science collaboration in international affairs. Public Understanding of Science, 26(6), 688-703.

Fernández-Esquinas, M., Pinto, H., Yruela, M. P., \& Pereira, T. S. (2016). Tracing the flows of knowledge transfer: Latent dimensions and determinants of university-industry interactions in peripheral innovation systems. Technological Forecasting and Social Change, 113, 266-279.

Fischer, B. B., Schaeffer, P. R., \& Silveira, J. P. (2018). Universities' gravitational effects on the location of knowledge-intensive investments in Brazil. Science and Public Policy, 45(5), 692-707.

Ghio, N., Guerini, M., \& Rossi-Lamastra, C. (2019). The creation of high-tech ventures in entrepreneurial ecosystems: exploring the interactions among university knowledge, cooperative banks, and individual attitudes. Small Business Economics, 52(2), 523-543.

Giunta, A., Pericoli, F. M., \& Pierucci, E. (2016). University-industry collaboration in the biopharmaceuticals: The Italian case. The Journal of Technology Transfer, 41(4), 818-840.

Goel, R. K., Göktepe-Hultén, D., \& Grimpe, C. (2017). Who instigates university-industry collaborations? University scientists versus firm employees. Small Business Economics, 48(3), 503-524.

Gonzales, L. D., Martinez, E., \& Ordu, C. (2014). Exploring faculty experiences in a striving university through the lens of academic capitalism. Studies in Higher Education, 39(7), 1097-1115.

Guerrero, M., Urbano, D., \& Herrera, F. (2019). Innovation practices in emerging economies: Do university partnerships matter?. The Journal of Technology Transfer, 44(2), 615-646. 
Guo, F., Restubog, S. L. D., Cui, L., Zhou, B., \& Choi, Y. (2019). What determines the entrepreneurial success of academics? Navigating multiple social identities in the hybrid career of academic entrepreneurs. Journal of Vocational Behavior.

Guzzini, E., \& Iacobucci, D. (2017). Project failures and innovation performance in university-firm collaborations. The Journal of Technology Transfer, 42(4), 865-883.

Haynes, R. D. (1989). The Scientist in Literature: Images and Stereotypes-Their Importance. Interdisciplinary Science Reviews, 14(4), 384-398.

Henningsson, M., \& Geschwind, L. (2019). Senior industry practitioners as part-time visiting professors: the various benefits of collaboration. Higher Education Policy, 32(1), 109-128.

Herbert, B. (2003). Dreamer of Dune: the biography of Frank Herbert. MacMillan.

Hrotic, S. (2014). The evolution and extinction of science fiction. Public Understanding of Science, 23(8), 996-1012.

Huszár, S., Prónay, S., \& Buzás, N. (2016). Examining the differences between the motivations of traditional and entrepreneurial scientists. Journal of Innovation and Entrepreneurship, 5(1), 25.

Huxford, J. (2000). Framing the future: science fiction frames and the press coverage of cloning. Continuum: Journal of Media \& Cultural Studies, 14(2), 187-199.

Johnson, D. R. (2018). The Boundary Work of Commercialists in Academe: Implications for Postdoctoral Training. The Journal of Higher Education, 89(4), 503-526.

Kalantaridis, C., Küttim, M., Govind, M., \& Sousa, C. (2017). How to commercialise university-generated knowledge internationally? A comparative analysis of contingent institutional conditions. Technological Forecasting and Social Change, 123, 35-44.

Kirby, D. (2010). The future is now: Diegetic prototypes and the role of popular films in generating realworld technological development. Social Studies of Science, 40(1), 41-70.

Kunttu, L., \& Neuvo, Y. (2019). Balancing learning and knowledge protection in university-industry collaborations. The Learning Organization, 26(2), 190-204.

Leischnig, A., \& Geigenmüller, A. (2018). Examining alliance management capabilities in universityindustry collaboration. The Journal of Technology Transfer, 1-22.

Lieb, K., \& Koch, C. (2013). Medical Students' Attitudes to and Contact with the Pharmaceutical Industry: A Survey at Eight German University Hospitals. Deutsches Ärzteblatt International, 110(35-36), 584. 
Locke, S. (2005). Fantastically reasonable: ambivalence in the representation of science and technology in super-hero comics. Public Understanding of Science, 14(1), 25-46.

Lundvall, B. Å. (Ed.). (2010). National systems of innovation: Toward a theory of innovation and interactive learning (Vol. 2). Anthem press.

Maietta, O. W. (2015). Determinants of university-firm R\&D collaboration and its impact on innovation: A perspective from a low-tech industry. Research Policy, 44(7), 1341-1359.

Marques, A. V., Marques, C., Braga, V., \& Marques, P. M. (2019). University-industry technology transfer within the context of RIS3 North of Portugal. Knowledge Management Research \& Practice, 1-13.

McCloskey, D. N. (2002). 16 You shouldn't want a realism if you have a rhetoric. Fact and Fiction in Economics: Models, Realism and Social Construction, 329.

McClure, K. R., \& Teitelbaum, K. (2016). Leading schools of education in the context of academic capitalism: Deans' responses to state policy changes. Policy Futures in Education, 14(6), 793-809.

Meng, D., Li, X., \& Rong, K. (2019). Industry-to-university knowledge transfer in ecosystem-based academic entrepreneurship: Case study of automotive dynamics \& control group in Tsinghua University. Technological Forecasting and Social Change, 141, 249-262.

Meyer-Krahmer, F., \& Schmoch, U. (1998). Science-based technologies: university-industry interactions in four fields. Research policy, 27(8), 835-851.

Miller, C. A., \& Bennett, I. (2008). Thinking longer term about technology: is there value in science fiction-inspired approaches to constructing futures?. Science and Public Policy, 35(8), 597-606.

Molas-Gallart, J., Salter, A., Patel, P., Scott, A., \& Duran, X. (2002). Measuring third stream activities. Final report to the Russell Group of Universities. Brighton: SPRU, University of Sussex.

Mowery, D. C., Nelson, R. R., Sampat, B. N., \& Ziedonis, A. A. (2001). The growth of patenting and licensing by US universities: an assessment of the effects of the Bayh-Dole act of 1980. Research policy, 30(1), 99-119.

Nelson, R. R. (Ed.). (1993). National innovation systems: a comparative analysis. Oxford University Press on Demand.

Nowotny, H., Limoges, C., \& Gibbons, M. (1994). The new production of knowledge: The dynamics of science and research in contemporary societies. Sage Publications. 
Orazbayeva, B., Davey, T., Plewa, C., \& Galán-Muros, V. (2019). Engagement of academics in educationdriven university-business cooperation: a motivation-based perspective. Studies in Higher Education, 114.

Parker, I. A. (2015). Podemos as event or not: what it looks like from Manchester. Teknokultura, 12(1), $153-160$.

Partha, D., \& David, P. A. (1994). Toward a new economics of science. Research policy, 23(5), 487-521.

Pennacchio, L., Piroli, G., \& Ardovino, O. (2018). The Role of R\&D Cooperation in Firm Innovation. International Journal of Innovation and Technology Management, 15(01), 1850003.

Perkmann, M., Tartari, V., McKelvey, M., Autio, E., Broström, A., D’Este, P., ... \& Krabel, S. (2013). Academic engagement and commercialisation: A review of the literature on university-industry relations. Research policy, 42(2), 423-442.

Pick, D. (2017). Rethinking organization theory: The fold, the rhizome and the seam between organization and the literary. Organization, 24(6), 800-818.

Santoro, M. D., \& Chakrabarti, A. K. (2002). Firm size and technology centrality in industry-university interactions. Research policy, 31(7), 1163-1180.

Saviano, M., Barile, S., Farioli, F., \& Orecchini, F. (2019). Strengthening the science-policy-industry interface for progressing toward sustainability: a systems thinking view. Sustainability Science, 1-16.

Scandura, A. (2016). University-industry collaboration and firms’ R\&D effort. Research Policy, 45(9), 1907-1922.

Schot, J., \& Steinmueller, W. E. (2018). Three frames for innovation policy: R\&D, systems of innovation and transformative change. Research Policy, 47(9), 1554-1567.

Slaughter, S., Slaughter, S. A., \& Rhoades, G. (2004). Academic capitalism and the new economy: Markets, state, and higher education. JHU Press.

Spaapen, J., \& Van Drooge, L. (2011). Introducing 'productive interactions' in social impact assessment. Research evaluation, 20(3), 211-218.

Steinmueller, W. E. (2017). Science fiction and innovation: A response. Research Policy, 46(3), 550-553.

Takanashi, C., \& Lee, K. J. (2019). Boundary spanning leadership, resource mobilisation, and performance of university-industry R\&D projects: a study in a Japanese university. Technology Analysis \& Strategic Management, 31(2), 140-154. 
Terzian, S. G., \& Grunzke, A. L. (2007). Scrambled eggheads: ambivalent representations of scientists in six Hollywood film comedies from 1961 to 1965. Public Understanding of Science, 16(4), 407-419.

Thelwall, M. (2017). Book genre and author gender: romance> paranormal- romance to autobiography> memoir. Journal of the Association for Information Science and Technology, 68(5), 1212-1223.

Tijssen, R. J. (2018). Anatomy of use-inspired researchers: From Pasteur's Quadrant to Pasteur's Cube model. Research Policy, 47(9), 1626-1638.

Tijssen, R. J., Yegros-Yegros, A., \& Winnink, J. J. (2016). University-industry R\&D linkage metrics: validity and applicability in world university rankings. Scientometrics, 109(2), 677-696.

Vedovello, C. (1997). Science parks and university-industry interaction: geographical proximity between the agents as a driving force. Technovation, 17(9), 491-531.

Von Schomberg, R. (2013). A vision of responsible research and innovation. Responsible innovation: Managing the responsible emergence of science and innovation in society, 51-74.

Voutsinas, I., Tsamadias, C., Carayannis, E., \& Staikouras, C. (2018). Does research and development expenditure impact innovation? Theory, policy and practice insights from the Greek experience. The Journal of Technology Transfer, 43(1), 159-171.

Weingart, P., Muhl, C., \& Pansegrau, P. (2003). Of power maniacs and unethical geniuses: Science and scientists in fiction film. Public Understanding of Science, 12(3), 279-287.

Yegros-Yegros, A., Azagra-Caro, J. M., López-Ferrer, M., \& Tijssen, R. J. (2016). Do university-industry co-publication outputs correspond with university funding from firms?. Research Evaluation, 25(2), 136-150.

Zhang, G., Liu, L., \& Wei, F. (2019). Key nodes mining in the inventor-author knowledge diffusion network. Scientometrics, 118(3), 721-735. 